\title{
FIRST REPORT OF HALOBACTERIA DOMINANCE IN A TROPICAL CAVE MICROBIOME
}

${ }^{1}$ Department of Ecology and Evolutionary Biology, Federal University of São Carlos, São

9 Carlos, Brazil

10 2Department of Aquatic Microbial Ecology, Institute of Hydrobiology, Biology Centre CAS,

11 České Budějovice, Czech Republic

12 Department of Hydrobiology, Federal University of São Carlos, São Carlos, Brazil

14 State University, Jaboticabal, Brazil

* Correspondence:

16 Caio César Pires de Paula

17 caio.piresdepaula@hbu.cas.cz 


\section{Abstract}

Scarce studies on microbial diversity in tropical caves have been published, a subterranean system still neglected from a microbiological point of view. Although most published studies are about temperate caves, usually archaeas and fungi have less attention than bacterial communities. Here, the microbiome structure and composition in a tropical cave system, as well the main environmental drivers, were studied during the wet and dry season. Soil and sediments from three different habitats at the cave (surface, entrance cave and dark zone) were sampled. Samples were characterized (temperature, air and substrate humidity, salinity, $\mathrm{pH}$, nitrogen and organic carbon content, and chemical composition) and the microbiome was assessed by high-throughput sequencing, using amplicon sequencing (16S and ITS). Prokaryotic communities were dominated by Halobacteria, Actinobacteria and Bacilli, while fungal communities showed high abundance of Sordariomycetes. Microbiomes from the cave entrance, where a significantly elevated salinity levels were found, supported up to $63 \%$ of Haloarchaea compared to the other habitats studied. Differences in community structure were significant between habitats, but no influence of the season was observed. Main environmental drivers of community assembly included nitrogen and organic carbon content, temperature, and salinity. This is the first report of Halobacteria dominance in cave habitats, where they likely play important roles in nitrogen and phosphorus cycles. The cave entrance had lower diversity, but higher degree of microbial endemism, which characterize it as an important cave ecotone. The prevalence of heterotrophic microbial groups implies trophic structure based on detritivores, particularly in the dark zones. Our study brings new insights on microbiome composition in the underexplored tropical cave habitats. 


\section{INTRODUCTION}

Caves are generally classified as extreme environments due to the prevailing oligotrophy and lack of light to support photosynthesis. They therefore represent highly specialized ecosystems with no autochthonous photosynthesis-based primary production, dependent mostly on allochthonous carbon inputs [1]. Microbial biodiversity, function, and community dynamics in caves are still considered somewhat of a "black box". Although the number of published results on cave microbiology has increased over the past decade, most of them were based on temperate cave habitats, and the information on tropical caves are still scarce [2]. Tropical caves are in regions differing significantly in environmental conditions regarding the temperate caves, which include, in general, climate with higher temperatures, a dense tree canopy whole year, due the lack of a dormant period in the winter or dry season, and higher primary production [3]. Such differences can influence the structure and dynamics of microbial communities in caves [4 - 5], highlighting the importance to understand the microbial ecology in tropical cave environments over a seasonal cycle.

Even though the published literature covers a wide variety of microbial habitats within the caves such as soils, sediments, stream water, and rock surfaces, most information is limited to describing the Bacteria domain only. Indeed, caves show high abundances of Proteobacteria, presumably involved in nitrogen fixation, along with significant populations of Actinobacteria, with a suggested role in carbon turnover [6]. Nevertheless, studies evaluating the presence and dynamics of other microbial groups in the caves - the Archaea and Eukarya - are rare. Recently, after a microbiome definition update, researchers have highlighted the importance of considering all microorganisms belonging to different kingdoms

81 (prokaryotes: bacteria, archaea, and micro-eukaryotes: as fungi), as well as their functions and interactions, as part of microbiome studies [7]. 
Next generation sequencing technology advances in the last decade made it easier to assess the uncultured microbial diversity in cave environments and recent studies have demonstrated the presence of Archaea, most frequently from the phyla Thaumarchaeota and Euryarchaeota [8 - 10]. Methanogenic archaea (MA) and ammonia-oxidizing archaea (AOA) are the best-characterized archaeal groups and these microorganisms are targeted in studies of subterranean environments due to their ecological importance in biogeochemical cycling [11]. These microorganisms are involved in the terminal steps of carbon flows, nitrification processes [12], primary production [13], and denitrification [14] in terrestrial and aquatic environments. There are currently no Thaumarchaeota in culture. Although these are the most frequently encountered Archaea in caves, we have very limited information on the possible biogeochemical and ecological roles of Thaumarchaeota in these specific environments [11, 15 - 16]. Most of what we do know has been inferred from metagenomics studies: Thaumarchaeota are likely to play an important role in ammonia oxidation in temperate caves [10]. Some cave microbiomes contain a large proportion of Euryarchaeota. For instance, four Euryarchaeota classes - Methanomicrobia, Thermoplasmata, Halobacteria and Methanobacteria - were found in Indian caves systems [8]. The Euryarchaeota include extreme halophiles, sulfate reducers, thermophilic heterotrophs, and methanogens [17]. in caves worldwide [18]. The most identified fungi in caves belongs to the phyla Ascomycota,

102 Basidiomycota, and Zygomycota [19]; however, the relevance of these findings should be 103 viewed with caution, as these studies utilize cultivation-dependent techniques. The difficulty of laboratory cultivation, especially those fungi colonizing rocks or low metabolic activity, limits the knowledge of the real diversity, as well as the exploration of the ecological roles performed by these microorganisms in the cave systems. Cave fungi are decomposers or

107 parasites, although they can also aid in speleogenesis processes through the precipitation of 
secondary minerals [20]. Fungi are the main saprophytic organisms in cave systems and play an important role in the food web [19]. However, pathogenic fungi receive more attention in cave studies due to health and economic concerns, which mainly include Histoplasma capsulatum and Pseudogymnoascus destructans. view and ii) the gap in the information about achaeas and fungi in cave microbiomes, the main goal of the present study were the analysis the structure and composition of the microbiomes

115 (here including archaea, bacteria and fungi), in different habitats within a tropical cave system,

116 to evaluate the main environmental factors that drive the structure of the microbiomes, and to

117 discuss the possible role of the cave microorganisms in the trophic structure of the subterranean

118 habitats. This is the first research in Brazilian caves using new generation sequencing to assess

119 fungal and prokaryotic diversity. Belonging to the several larger karst areas in Brazil, Terra the main complex of cave systems in Brazil, including several superficial and subterranean drainages, with great potential for the transport of organic matter, causing accumulations of debris in some caves. This causes high habitat differentiation, accompanied by high richness of subterranean terrestrial and aquatic taxa [21 - 25]. Although the biology of these biodiversity hotspots, especially that of the subterranean fauna, is well known, no studies focused on the microbial assemblages were published so far.

MATERILAS AND METHODS

\subsection{STUDY SITE}


134 formed by rivers arriving from the Serra Geral Plateau, a morphological feature that originated

135 in the Cretaceous, in the sandstones of the Urucuia Formation [26]. The PETeR is a karst area

136 crossed by parallel streams running westwards to join the Paraná River, a tributary of the Upper

137 Tocantins River, in the Amazonas Basin. The study area belongs to the Cerrado

138 phytogeographical domain (a savanna-like vegetation). The climate is tropical semi-humid

139 with a mean annual precipitation of about $1270 \mathrm{~mm} \mathrm{yr}^{-1}$ [27]. The wet season extends from

140 November to April, with rainfall essentially absent between May and October (dry season).

141 Although the area is a Conservation Unit, the park is threatened by anthropogenic impact, such

142 as deforestation for agriculture and uncontrolled tourism, and the springs of the main rivers are

143 outside the boundary of the Conservation Unit, a place used for cattle, crops, consequently

144 silting and polluting rivers and affecting the cave systems [28].

145 The Lapa da Terra Ronca I cave (TR cave) is a part of the Terra Ronca-Malhada cave

146 system (Fig 1, Fig S1). The cave has an entrance of ca 100 meters high and 120 meters wide,

147 with a built altar measuring 760 meters long and 100 meters high where the local religious

148 ceremony of "Bom Jesus da Lapa" takes place at the beginning of August.

Samplings were conducted in April 2016 (wet season) and October 2016 (dry season)

152 (license $n^{\circ}$ 28992-11/ICMBio/SISBIO and $n^{\circ}$ 14886/2010/Secima, Goiás). One square of 153 approximately $0.25 \mathrm{~m}^{2}$ was sampled in three distinct habitats of the cave: surface (cave exterior

154 - around 50 meters far from cave entrance), cave entrance and the dark zone (no sunlight). All 155 the different habitats were sampled in replicates. Approximately $300 \mathrm{~g}$ of substrate (soil or cave sediment, up to $10 \mathrm{~cm}$ in depth) were collected at five different points of the square area at each

157 site forming a composite sample. Samples were collected with the aid of a shovel and stored in 
sterile plastic bags. The samples were transported to the laboratory in coolers, homogenized, sieved ( $2 \mathrm{~mm}$ mesh) and stored in the refrigerator at $4{ }^{\circ} \mathrm{C}$.

\subsection{PHYSICAL AND CHEMICAL PARAMETERS}

sampled area with a minimum time interval of 1 minute between measurements (Thermoestimated by the gravimetric method with drying at $105^{\circ} \mathrm{C}$ for $20 \mathrm{~h}$ to 7 days after sampling, and the results expressed as dry weight percentage. Organic carbon (OC) concentrations were measured colorimetrically using the method of [29]. Total nitrogen content (TN) was microscopy (SEM), together with chemical analysis by energy dispersive spectroscopy (EDS).

173 An Oxford EDS coupled to a FEI Quanta 250 SEM was used to examine the chemical composition of the samples. The substrate was adhered to a double-sided copper tape mounted spectra of elements were acquired for each sample on average.

\subsection{DNA EXTRACTION AND SEQUENCING}

DNA was extracted from $0.25 \mathrm{~g}$ of each homogenized sample using the MoBio

180 PowerSoil DNA extraction kit (MoBio Laboratories, Carlsbad, CA, USA) following 181 manufacturer's instructions. The quality and quantity of extracted DNA were verified by the 182 examining products on TBE agarose gels and by measuring the ratio of absorbance at 260 and 
$280 \mathrm{~nm}$, and 260 and $230 \mathrm{~nm}$, with a Thermo Scientific Nanodrop 2000c Spectrophotometer. For prokaryotes, the V3-V4 region of the $16 \mathrm{~S}$ rDNA genes was amplified using the primer pair $\quad 341 \mathrm{~F}$ (5'-CCTACGGGNGGCWGCAG-3') and $805 \mathrm{R}$ GACTACHVGGGTATCTAATCC-3'). The ITS1 (5'-GCATCGATGAAGAACGCAGC-3') / ITS4 (5'-TCCTCCGCTTATTGATATGC-3') primers were used to assess the diversity of fungi [32 - 33]. Briefly, for a $25 \mu \mathrm{L}$ PCR reaction with $8.5 \mu 1$ of Kapa High-fidelity HOTSTART ready MIX, $0.1 \mu \mathrm{M}$ of each primer, $10 \mu \mathrm{l}$ of PCR-grade water, and 10 ng of DNA extract were used. The $16 \mathrm{~S}$ rDNA amplification conditions were $95^{\circ} \mathrm{C}$ for $3 \mathrm{~min}$, followed by 35 cycles at $95{ }^{\circ} \mathrm{C}$ for $30 \mathrm{~s}, 55^{\circ} \mathrm{C}$ for $1 \min 15 \mathrm{~s}, 72^{\circ} \mathrm{C}$ for $45 \mathrm{~s}$, and finally $72^{\circ} \mathrm{C}$ for $5 \mathrm{~min}$. The ITS amplification had an initial stage of $95^{\circ} \mathrm{C}$ for $3 \mathrm{~min}, 35$ cycles of $95^{\circ} \mathrm{C}$ for $15 \mathrm{~s}, 60^{\circ} \mathrm{C}$ for 15 $\mathrm{s}, 72{ }^{\circ} \mathrm{C}$ for $45 \mathrm{~s}$, and finally $72{ }^{\circ} \mathrm{C}$ for $10 \mathrm{~min}$. PCR products were purified with the AMPURE XP magnetic bead kit (Bechman Coulter) and indexed with the Nextera XT kit V2 (Illumina) to separate samples for sequencing. A second step of purification with magnetic beads followed, and then the metagenomic pool was assembled with $5 \mu 1$ of each library. Highthroughput sequencing of the V3-V4 and ITS regions was performed using the Illumina MiSeq sequencing platform. ITS amplicons were sequenced at Macrogen (Macrogen Inc., Seoul, Korea), while the $16 \mathrm{~S}$ samples at the Multi-user Laboratory of Sequencing in Large Scale and Gene Expression (São Paulo State University "Julio de Mesquita Filho"). Negative extraction and PCR controls were sequenced together with amplicons samples, and the raw sequences have been deposited in the NCBI Sequence Read Archive (SRA) under project accession number PRJNA723998 (16S) and PRJNA724003 (ITS).

\subsection{BIOINFORMATIC ANALYSIS AND BIODIVERSITY ASSESMENT}

Sequencing data were processed using UPARSE [34] in a pipeline internally implemented for 16S and ITS [35]. Paired-end reads were merged with PEAR [36]. Sequences 
were quality controlled with the following steps: all sequences shorter than $100 \mathrm{pb}$ were discarded, followed by quality dereplication checking, OTU clustering (UPARSE algorithm, similarity $\geq 97 \%$ ), and filtering of chimeras with USEARCH [37 - 38]. Taxonomic

211 classification was performed through BLASTn using the databases SILVA 119.1 for 16S and

212 UNITE for ITS.

213 All statistical analyses were carried out in R Software (R. Core Team, 2016).

214 Environmental variables were analyzed using basic descriptive statistic (Shapiro-Wilks).

215 Analysis of variance and Student t-tests with 5\% probability threshold were also applied to

216 verify the significance of the differences among the results. Statistical analyses of microbial

217 community richness, alpha diversity (Shannon index) and community structure were estimated

218 using $\mathrm{R}$ microbiome package [39]. The distance matrices of community composition were

219 obtained using Bray-Curtis distance and, for environmental matrices, Euclidean distance was used. Relationship between environmental and microbiomes matrices were evaluated by Canonical Correspondence Analysis (CCA) using tools from a number of other R extensions, including vegan [40] and ggplot2 [41]. Differences among sites sampled and the two seasons were tested using permutational multivariate analysis of variance (PERMANOVA) with BrayCurtis distance, performing 9999 permutations using the adonis function [40]. Principal coordinate Analysis (PCoA) ordination using weighted Unifrac was used to evaluate the $\beta$ diversity among the sampled sites and a heatmap associated with cluster analyzes (pheatmap

227 function) to identify biomarkes for each habitat [42]. 


\section{$233 \quad 3 \quad$ RESULTS}

\subsection{PHYSICOCHEMICAL PARAMETERS}

A summary of all analyzed environmental variables is presented in Table 1 . The two difference most pronounced in the dry season (4.42\%, compared to $2.36 \%$ in the wet season).

240 The substrate in all samples were slightly alkaline ( $\mathrm{pH}$ ranged between 7.49 and 8.88), and there was a marked trophic gradient present in both (wet and dry) sampling season: higher organic carbon content at the cave entrance $\left(1008.20 \mathrm{mgC} \mathrm{kg}^{-1}\right.$ and $1170.71 \mathrm{mgC}_{\mathrm{kg}}{ }^{-1}$, respectively), followed by the surface $\left(820.37 \mathrm{mgC} \mathrm{kg}^{-1}\right.$ and $\left.824.48 \mathrm{mgC} \mathrm{kg}^{-1}\right)$, and the dark zone site with lowest measured organic carbon concentrations $\left(448.93 \mathrm{mgC} \mathrm{kg}^{-1}\right.$ and 334.98 $\mathrm{mgC} \mathrm{kg}-1)$. The surface showed higher amounts of TN in the dry season $\left(0.075 \mathrm{mgN} \mathrm{kg}^{-1}\right)$, while higher amounts of $\mathrm{TN}$ at the entrance and dark zone sites were observed in the wet season (0.078 $\mathrm{mgN} \mathrm{kg}^{-1}$ and $0.036 \mathrm{mgN} \mathrm{kg}^{-1}$, respectively). The detailed analysis of sample chemical composition revealed that silica $(\mathrm{Si})$ was the dominant element. The cave entrance exhibited higher concentration of other essential elements, such as magnesium $(\mathrm{Mg})$ and calcium $(\mathrm{Ca})$

250 (Table 2). Samples from there were also the only ones where chlorine (Cl), sulfur (S), and phosphorus $(\mathrm{P})$ were present in detectable quantities.

\subsection{MICROBIOME COMPOSITION}

A total of 12 samples from three different habitats (surface, entrance, and dark zone) at

TR cave were sequenced by Illumina MiSeq platform, resulting in 1,156,899 sequences for

256 prokaryotic communities. After contig assembly, trimming, and chimera removal a total of 
taxonomically annotated from phylum to genus levels (S2 Appendix). The archaea and domains (44.06\% archaea and 55.94\% bacteria), differing significantly in this respect from the dark zone $(6.62 \%$ archaea and $93.38 \%$ bacteria $)$ and the surface $(0.68 \%$ archaea and 99.32\% bacteria). Particularly the cave entrance showed a larger archaea community in the dry season $(75.49 \%$ archaea and $24.51 \%$ bacteria) than in the wet season $(30.61 \%$ archaea and samples. Halobacteria was the dominat class in archaeal communities, with Halalkalicoccus

$267(54.52 \%)$ and Halococcus $(29.46 \%)$ as the most representative taxa. Actinobacteria were dominant at the surface and dark zone sites, while Bacilli was the dominant bacterial class at the cave entrance. Fig 2A shows the main prokaryotic classes found at the sampling sites. Uncultured prokaryotic taxa comprised $24.22 \%$ at the genus level. A total of $32.5 \%$ of prokaryotic OTUs was shared between the sites, with surface showing a higher proportion of unique OTUs (16.6\%), followed by the cave entrance (15.4\%) and the dark zone (3.5\%). About $64.4 \%$ of the prokaryotic OTUs were present in both sampling seasons. three different habitats ranged from 89,340 reads (surface) to 105,820 reads (entrance), with

$2773 \%$ cutoff. In total, 415 known genera, 193 known families, 76 known orders and 30 known 278 classes in 7 fungal phyla were detected in the TR cave samples. Ascomycota was the most 279 dominant phylum, with the relative abundance of $77.54 \%$, followed by Basidiomycota (8.21\%),

280 Chytridiomycota (0.37\%), Mortierellomycota (0.36\%), Mucoromycota (0.01\%),

281 Glomeromycota (0.002\%), and Rozellomycota (0.001\%). The relative abundance of 10 most 282 detected fungal taxa at the class level for all samples is showed in Fig 2B. The dataset contained 
fungal sequences unidentifiable at the phylum and class level $(13.49 \%$ and $14.37 \%$, dark zone site was unidentified at phylum level (11.73\%) and was followed by an Aspergillus sp. (SH186265.07FU) (6.61\%). Only 3.4\% OTUs were present in all sampled habitats, with higher proportion of unique OTUs at the cave entrance (42.6\%) and dark zone (25.9\%). About $17.1 \%$ of the fungal OTUs were present in both seasons, while $45.6 \%$ and $37.3 \%$ of the OTUs were unique in the wet and dry season samples, respectively.

\subsection{MICROBIOME STRUCTURE AND ENVIRONMENTAL DRIVERS}

The microbiome structure varied significantly among the different habitats

(PERMANOVA, F2 $=1.59, \mathrm{p}=0.001$ ), with no effect of the season (PERMANOVA, F2 =

$0.70, \mathrm{p}=0.94)$. The same pattern can be observed analyzing only prokaryotic (PERMANOVA,

$\mathrm{F} 2=1.63, \mathrm{p}=0.02)$ or fungal (PERMANOVA, $\mathrm{F} 2=1.34, \mathrm{p}=0.004)$ communities from the

sampling sites. Based on these results, the season factor was excluded from the following analyses and the microbiome was considered as a whole, i.e. containing both prokaryotic and fungal assemblages.

followed by the dark zone $(1,627.45 \pm 1,101.80)$ and entrance samples $(1,541.22 \pm 478.32)$. In contrast, the Shannon index indicated that dark zones $(4.38 \pm 0.67)$ and surface $(4.32 \pm 0.69)$

303 had higher microbial diversity than the cave entrance $(3.86 \pm 0.87)$. Surface samples showed a

304 slightly increased Simpson dominance $(0.08 \pm 0.08)$ compared to the entrance $(0.07 \pm 0.03)$ and dark zone $(0.04 \pm 0.02)$ samples. A cluster analysis of OTU-level diversity and PCoA based on weighted Unifrac results both showed distinct grouping of samples according to the different cave habitats, with the cave entrance cluster falling between the surface and the dark zone (Fig 
4A). Overall, the core assemblage associated with each cave habitat showed a degree of specificity (heatmap analysis, Fig 5): Cladosporium sphaerospermum (Dothideomycetes) and Torula sp. (Saccharomycetes) were characteristic for surface samples, Aspergillus sp.

311 (Eurotiomycetes) and Bovista aestivalis (Agaricomycetes) for the dark zone, while the cave

312 entrance samples contained up to eight highly specific OTUs including Rubrobacter sp.

313 (Rubrobacteria), Halalkalicoccus tibetensis (Halobacteria), Cladosporium sp.

314 (Dothideomycetes), Aspergillus sp. (Eurotiomycetes), Cladosporium halotolerans

315 (Dothideomycetes), Capnodiales sp. (Dothideomycetes), Halalkalicoccus sp. and Halococcus 316 sediminicola (Halobacteria).

317 Canonical Correspondence Analysis (CCA) was used to identify possible relationships 318 between microbial assemblages and local physicochemical variables at sampling sites (Fig 4B).

319 The analysis of variance using distance matrices was used to find the best set of environmental variables that describe the community structure for each site sampled $(\mathrm{p}<0.05)$. Among the tested variables, nitrogen $(\mathrm{F} 2=1.96, \mathrm{p}=0.01)$, temperature $(\mathrm{F} 2=1.49, \mathrm{p}=0.01)$, organic carbon $(\mathrm{F} 2=2.02, \mathrm{p}=0.01)$, and salinity $(\mathrm{F} 2=1.34, \mathrm{p}=0.02)$ were the main environmental drivers affecting the distribution of microorganisms. The variables showed a positive correlation with microbiomes at the cave entrance, while the surface and dark zone sites showed an opposite trend. These results clearly show a trophic and salinity gradient affecting the microbial structures at the cave entrance in relation to the other habitats.

\section{DISCUSSION} although this is largely based on research results on temperate cave environments. However, this assumption of oligotrophic conditions only holds true for subterranean environments that are relatively isolated from the surface, thus having very limited organic input [43]. The TR 
cave entrance and dark zone sites are relatively well connected with the surface environment,

which is a rich source of organic matter as it is characterized by dense vegetation cover. This

is reflected in the concentrations of organic carbon, which seems to accumulate at the cave entrance, with its concentration at dark zone site high, in the range of $100 \mathrm{mg} \mathrm{g}^{-1}$. This supports the conclusions of recent research that although both temperate and tropical cave communities are supported by organic inputs from allochthonous sources, and both types of systems show a trophic gradient from surface to dark zones, the tropical subterranean environments are not

341 limited in energy input to the same degree as their temperate counterparts, due to the diversity

342 and abundance of vegetation and its presence throughout the whole year [3, 5]. The

343 environmental differences between tropical and temperate caves directly influenced the

344 microbial communities within subterranean system. Tropical caves are a particularly understudied environment, and most of what we know about microbial communities was based on studies using culture-dependent methods [44 - 47]. While there are some published results generated by culture-independent approaches $[6,48]$, this is the first comprehensive study reporting the microbiome composition from a tropical cave, including prokaryotic and fungal assemblages through next generation sequencing.

TR cave sites hosted a heterotrophic microbiome and most of the dominant phyla identified in this study were previously also found in other cave systems worldwide (summarized in [2]). Actinobacteria and Sordariomycetes were the dominant classes at the dark zone site, which seems to be a general trend in limestone caves [4, 49]. Actinobacteria are

354 known as typical heterotrophs, that play a crucial role in the carbon cycling through organic matter decomposition [50], and good competitors due to their wide metabolic capabilities

357 produce several secondary metabolites, such as antibiotics [51, 52]. Sordariomycetes 358 (Ascomycota), although their diversity remains underestimated, represent a recurrent fungal 
class in caves which also likely play an important role in the decomposition of organic matter,

with their biomass (spores and mycelia) as an essential food source for many cave arthropod show an aggressive colonization strategy, capable of surviving in extreme environmental conditions, and some fungi of this class, such as Penicillium and Aspergillus, are able to degrade rocks and solubilize minerals [53]. All these features regarding to cave microbiome are an important advantage to survive in low carbon and nutrient environments, as in dark zone results. However, caves can present opportunistic fungi, which can be pathogenic under specific conditions, such as high concentrations of spores and dry air. Fungi species responsible for opportunistic infections have increased in recent decades [54]. Aspergillus fumigatus, for instance, was found in all sampled habitats and high abundance in entrance at the TR cave. Aspergillus fumigatus, an opportunistic fungus, is the main responsible for aspergillosis and it is necessary to inhale a high load of spores to develop the disease. Spores inhaled by healthy people are eliminated quickly by the immune system or just a weak allergy is developed. On the other hand, people with compromised immune systems can develop a serious pulmonary infection by inhaling a large load of spores [55]. Periodic monitoring of spore loads in TR cave is highly recommended in order to prevent people from entering the cave during periods with

378 a high concentration of spores in the air, especially in drier periods. The use of cave for tourism

379 and scientific purposes with no proper monitoring can lead to health problems for tourists, tour guides and researchers. 
$\mathrm{MgCl}_{2}$ that unfold proteins and increase solubility of hydrophobic chemicals [56], which makes the environment inhospitable for many microorganisms. Thus, the salinity can affect microbial

to be significantly higher at the cave entrance. Besides being a subterranean biodiversity hotspot, TR cave also has a cultural and religious value for the population from cities around the State Park of Terra Ronca. Since 1920, an annual religious festival attracts thousands of people to the cave entrance in August (dry season), and during this period the soil and sediment are highly compacted. In addition, fireworks containing residues rich in sulphur, potassium, and magnesium are used in large quantities [58]. Therefore, there are three factors possibly contributing to the increased salinity at this particular site: i) intense solar radiation at the cave entrance in comparison to the other two studied habitats and the consequent increase in water evaporation from the sediment; ii) sediment compaction during the religious festival decreases water retention and increases salt concentration in the substrate; and iii) intense and prolonged use of fireworks release salt-containing residues which accumulate in the sediment. All of these factors likely had an important effect on the microbiome composition and supported the dominance of halo-tolerant microorganisms at this site.

A significantly higher proportion of archaea, which surprisingly exceeded bacteria in relative abundance during the dry season, was found at the cave entrance site. The few research that has assessed archaeal diversity in caves emphasize the ecological importance of this group 403 in subterranean environments due to their involvement in biogeochemical cycling, especially 404 nitrogen and phosphorus [6, 8, 10]. Organisms belonging to the class Halobacteria 405 (Euryarchaeota) were the dominant group here, being commonly found in environments with salinity higher than $3 \%$ and preference for neutral to alkaline $\mathrm{pH}$ [59], have an important role

407 on nitrogen cycling - reducing nitrate and growing by denitrification [60], and hydrolyse 408 insoluble phosphorus compounds to soluble compounds that can easily be assimilated by other 
organisms [61]. They are facultative phototrophic due the presence of an integral membrane

410 protein known as bacteriorhodopsin [60, 62], a light-driven proton pump converting light

411 energy into chemical energy, which may aid the growth under anoxic conditions, such as in a

412 compacted sediment. All of these features highlighted the survival advantages of the

413 Halobacteria at the cave entrance: presence of detectable inorganic phosphorus, under osmotic

414 stress and anthropogenic disturbance.

415 Within the bacteria domain, Bacilli was the dominant class at the cave entrance,

416 similarly to the prevalence reported from other cave systems, namely the Ozark cave, USA

417 [51], and Brazilian caves [48]. Interestingly, in the Ararat Plain (Armenia), which represent a

418 hydromorphic saline-alkaline soils, resembling those at the entrance of TR cave, the bacterial community was reported to be highly reduced, almost limited solely to Bacilli, which are able to remain viable and growing without competition from other bacteria [63]. Under such conditions, Bacilli show a specific survival strategy which includes the synthesis of special desiccation-resistant proteins, the accumulation of non-reducing sugars and the formation of dormant life stages (endospores). In terms of fungi, Cladosporium halotolerans, known as black fungi, also showed high prevalence at the cave entrance and this result is likewise consistent with the measured environmental conditions. This organism has been isolated from mine water in the Iron Quadrangle region (Minas Gerais, Brazil), is well adapted to harsh oligotrophic habitats on the surface and subsurface of rocks [64], high radiation, low water availability, long periods of desiccation, and shows high potential for removing $\mathrm{Mn}$ from the environment [65]. Thus, the microbiome at the cave entrance clearly shows the highest degree of microbial specialisation compared to the two other studied sites. organic carbon, nitrogen, temperature, and salinity as the main environmental drivers in the 
structure of microbial communities. Salinity was strongly related to the structure of the microbiome at the entrance cave, as previously discussed, and the others environmental drivers were related to dominant saprophytic microorganisms at surface and dark zone. Previous study at TR cave revealed the availability of carbon and nitrogen influenced the microbial strategies

438 for organic matter decomposition and incorporation of those compounds into their biomass [5].

439 Now our results also support these environmental factors also influence the composition and 440 structure of the microbial communities. The entrance of TR cave can be considered as an 441 ecotone, the transitional zone between adjacent ecological systems (surface and dark zone), 442 where the environment rapidly shifts from one type to another based on abiotic and/or biotic

443 features. Even though many researchers consider ecotone an area with greater richness and 444 diversity than each one of the systems, an ecotone can also support lower diversity if resources vary widely within it or if it is in an area under the influence of severe disturbances [66]. The anthropogenic impact and the unique habitat conditions, such high salinity and solar radiation, at the entrance of TR cave can promote the development of high endemism and dominance of few species, as already seen for invertebrate community in caves [67].

In summary, this study is the first to assess the microbiome structure in different habitats of a tropical cave system using high-throughput amplicon sequencing. The 451 microbiomes at the surface and dark zone are composed mainly of heterotrophs 452 microorganisms. This composition together with the relatively high organic carbon 453 concentrations indicate the presence of a trophic network based almost entirely on detritivory.

454 The influence of carbon and nitrogen, as seen in previous studies in TR cave, along with temperature, highlights those as the main drivers on the decomposing microorganisms, especially in the dark zone. Our study also shows for the first time the dominance of Haloarchea

457 in a limestone cave, which may have an important ecological role in this environment as a 458 phototrophic, phosphate solubilizing archaea, and nitrogen cycle players. Furthermore, these 
results show that anthropogenic changes can have profound implications for cave soil

460 composition, microbiome structure, and, hence ecosystem functioning, should be considered

461 in the future studies, alongside the commonly researched effects on micro- and

462 macroinvertebrates and vertebrates.

463

\section{Acknowledgments}

465

466 This study was financed in part by the Coordenação de Aperfeiçoamento de Pessoal de Nível

467 Superior - Brasil (CAPES) - Finance Code 001, Fundação de Amparo à Pesquisa do Estado de

468 São Paulo (FAPESP, 2015/24763-9) for funding and supporting the project. We also thank

469 Ramiro Hilário dos Santos, Jonas Eduardo Gallão, Maria José Rosendo da Costa and all

470 member from the Laboratory of Subterranean Studies for assisting in the field sampling. We

471 appreciate the Grupo Bambuí de Pesquisas Espeleológicas (GBPE) for use permission of the

472 maps and the environmental agencies for the permission to collect: Biodiversity Authorization

473 and Information System / Chico Mendes Institute for Biodiversity Conservation (SISBIO /

474 ICMBIO); Goiás - Secretary of Environment, Water Resources, Infrastructure, Cities and

475 Metropolitan Affairs (SECIMA). The authors are grateful to the Postgraduate Program in

476 Ecology and Natural Resources (PPGERN/UFSCar) for the infrastructure. We thank Angélica

477 Maria Penteado Martins Dias and Luciana Bueno dos Reis Fernandes

478 (INCT-HYMPAR/UFSCar) for the chemical analysis of the substrates by scanning electron 479 microscopy (SEM) coupled to energy dispersive spectroscopy (EDS).

4816 Reference

482 [1] Ravn NR, Michelsen A, Reboleira ASP. Decomposition of organic matter in caves. Front. 483 Ecol. Evol. 2020; 8: 348. doi: 10.3389/fevo.2020.554651

484 [2] Hershey OS, Barton HA. The microbial diversity of caves. In: Moldovan OT, Kováč L, 485 Halse S, editors. Cave Ecology. Cham: Springer; 2018. pp. 69-90.

486 [3] Malhi Y, Doughty C, Galbraith D. The allocation of ecosystem net primary productivity in 487 tropical forests. Phil. Trans. R. Soc. B. 2011; 366: 3225-3245. doi: 10.1098/rstb.2011.0062 
[4] Yun Y, Wang H, Man B, Xiang X, Zhou J, Qiu X, et al. The relationship between pH and bacterial communities in a single karst ecosystem and its implication for soil acidification. Front. Microbiol. 2016; 7:1955. doi: 10.3389/fmicb.2016.01955

491 [5] Paula CCP, Bichuette ME, Seleghim MHR. Nutrient availability in tropical caves 492 influences the dynamics of microbial biomass. MicrobiologyOpen 2020; 9(7): e1044. doi: $10.1002 / \mathrm{mbo} 3.1044$

[6] Barton HA, Giarrizzo JG, Suarez P, Robertson CE, Broering MJ, Banks ED, et al. Microbial diversity in a Venezuelan orthoquartzite cave is dominated by the Chloroflexi (Class

496 Ktedonobacterales) and Thaumarchaeota Group I. 1c. Front. Microbiol. 2014; 5: 615. doi: 10.3389/fmicb.2014.00615

498 [7] Berg G, Rybakova D, Fischer D, Cernava T, Vergès MCC, Charles T, et al. Microbiome definition re-visited: old concepts and new challenges. Microbiome 2020; 8(1): 1-22. doi:

[8] Mandal S, Panda AK, Bisht SS, Kumar NS. MiSeq HV4 16S rRNA gene analysis of bacterial community composition among the cave sediments of Indo-Burma biodiversity hotspot. Environ. Sci. Pollut. Res. 2016; 23(12): 12216-12226. doi: 10.1007/s11356-016-64239

505 [9] Reitschuler C, Spötl C, Hofmann K, Wagner AO, Illmer P. Archaeal distribution in 506 moonmilk deposits from alpine caves and their ecophysiological potential. Microb. Ecol. 2016; 507 71(3): 686-699. doi: 10.1007/s00248-015-0727-z

508 [10] Anda D, Krett G, Makk J, Márialigeti K, Mádl-Szonyi J, Borsodi AK. Comparison of 509 bacterial and archaeal communities from different habitats of the hypogenic Molnár János Cave 510 of the Buda Thermal Karst system (Hungary). J. Caves Karst Stud. 2017; 79(2): 113-121. 511 doi:10.4311/2015MB0134

512 [11] Zhao R, Wang H, Yang H, Yun Y, Barton HA. Ammonia oxidizing archaea dominant 513 over bacterial ammonia oxidizers within alkaline cave sediments. Geomicrobiol. J. 2016; 34 : $514 \quad 511$ - 523. doi: 10.1080/01490451.2016.1225861 
515 [12] Tourna M, Stieglmeier M, Spang A, Koenneke M, Schintlmeister A, Urich T, et al.

516 Nitrososphaera viennensis, an ammonia oxidizing archaeon from soil. Proc. Natl. Acad. Sci.

517 2011; 108: 8420-8425. doi: 10.1073/pnas.1013488108

518 [13] Yakimov MM, La Cono V, Smedile F, DeLuca TH, Juarez S, Ciordia S, et al. Contribution

519 of crenarchaeal autotrophic ammonia oxidizers to the dark primary production in Tyrrhenian

520 deep waters (central Mediterranean Sea). ISME J. 2011; 5:945-961. doi:

$521 \quad 10.1038 /$ ismej.2010.197

522 [14] Zhu X, Burger M, Doane TA, Horwath WR. Ammonia oxidation pathways and nitrifier 523 denitrification are significant sources of $\mathrm{N}_{2} \mathrm{O}$ and $\mathrm{NO}$ under low oxygen availability. Proc. Natl.

524 Acad. Sci. 2013; 110: 6328-6333. doi: 10.1073/pnas.1219993110

525 [15] Tetu SG, Breakwell K, Elbourne LD, Holmes AJ, Gillings MR, Paulsen IT. Life in the 526 dark: metagenomic evidence that a microbial slime community is driven by inorganic nitrogen metabolism. ISME J. 2013; 7(6): 1227. doi: 10.1038/ismej.2013.14

[16] Ortiz M, Legatzki A, Neilson JW, Fryslie B, Nelson WM, Wing RA, et al. Making a living while starving in the dark: metagenomic insights into the energy dynamics of a carbonate cave. ISME J. 2014; 8: 478 - 491. doi: 10.1038/ismej.2013.159

531 [17] Bintrim SB, Donohue TJ, Handelsman J, Roberts GP, Goodman RM. Molecular 532 phylogeny of Archaea from soil. Proc. Natl. Acad. Sci. 1997; 94(1): 277-282. doi: 533 10.1073/pnas.94.1.277

534 [18] Zhang ZF, Zhao P, Cai L. Origin of cave fungi. Front. Microbiol. 2018; 9: 1407. doi: $535 \quad 10.3389 /$ fmicb.2018.01407

536 [19] Vanderwolf KJ, Malloch D, McAlpine DF, Forbes GJ. A world review of fungi, yeasts, 537 and slime molds in caves. Int. J. Speleol. 2013; 42: 77-96. doi: 10.5038/1827-806X.42.1.9

538 [20] Rawat S, Rautela R, Johri B N. Fungal world of cave ecosystem. In: Satyanarayana T, 539 Deshmukh SK, Johri BN, editors. Developments in fungal biology and applied mycology. 540 Singapore: Springer; 2017. pp. 99-124.

541 [21] Trajano E, Majer AP, Santos FB, Basile PA. Invertebrados aquáticos de cavernas da área 542 cárstica de São Domingos, nordeste de Goiás. O Carste 2003; 15(4), 126-131. 
543 [22] Bichuette ME, Trajano E. Epigean and subterranean ichthyofauna from the São Domingos

544 karst area, Upper Tocantins River basin, Central Brazil. J. Fish Biol. 2003; 63(5): 1100-1121. doi: 10.1046/j.1095-8649.2003.00227.x

546 [23] Simões MH, Souza-Silva M, Ferreira RL. Cave physical attributes influencing the 547 structure of terrestrial invertebrate communities in Neotropics. Subterr. Biol. 2015; 16: 103. 548 doi: $10.3897 /$ subtbiol.16.5470

549 [24] Bichuette ME, Simões LB, von Schimonsky DM, Gallão JE. Effectiveness of quadrat 550 sampling on terrestrial cave fauna survey-a case study in a Neotropical cave. Acta Sci. Biol. Sci. 2015; 37(3): 345 - 351. doi: 10.4025/actascibiolsci.v37i3.28374

552 [25] Bichuette ME, Simões LB, Zepon T, Gallo JE. Richness and taxonomic distinctness of 553 cave invertebrates from the northeastern state of Goiás, central Brazil: a vulnerable and singular area. Subterr. Biol. 2019; 29:1. doi: 10.3897/subtbiol.29.30418

[26] Auler A, Farrant AR. A brief introduction to karst and caves in Brazil. Proc. Univ. Bristol Spelaeol. Soc. 1996; 20: 187-200.

[27] Moquet JS, Cruz FW, Novello VF, Stríkis NM, Deininger M, Karmann I, et al. Calibration of speleothem $\delta 18 \mathrm{O}$ records against hydroclimate instrumental records in Central Brazil. Glob. Planet. Change. 2016; 139: 151-164.

560 [28] Gallão JE, Bichuette ME. A lista de fauna ameaçada de extinção e os entraves para a 561 inclusão de espécies-o exemplo dos peixes troglóbios brasileiros. Natureza \& Conservação $562 \quad 2012 ; 10(1): 83-87$.

563 [29] Bartlett RJ, Ross DN. Colorimetric determination of axidazable carbon in acid soil 564 solutions. Soil Sci. Soc. Am. J. 1988; 52: 1191-1192. doi: $565 \quad 10.2136 /$ sssaj1988.03615995005200040055x

566 [30] Bremmer JM, Mulvaney CS. Total nitrogen. In: Miller RH, Keeney DR, editors. Methods of soil analysis. Madison: American Society on Agronomy; 1982. pp 595-624.

568 [31] Zhai Y, Fu Z, Wang L, Zeng G, Li C, Chen H, Lu P. Characteristic, composition, and sources of TSP investigated by HRTEM/EDS and ESEM/EDS. Environ. Monit. Assess. 2012; 184(11): 6693-6707. doi: 10.1007/s10661-011-2452-5 
571 [32] White TJ, Bruns T, Lee SJWT, Taylor J. Amplification and direct sequencing of fungal ribosomal RNA genes for phylogenetics. PCR protocols: a guide to methods and applications 1990; 18(1): 315-322.

574 [33] Herlemann DP, Labrenz M, Jürgens K, Bertilsson S, Waniek JJ, Andersson AF. 575 Transitions in bacterial communities along the $2000 \mathrm{~km}$ salinity gradient of the Baltic Sea. ISME J. 2011; 5(10): 1571. doi: 10.1038/ismej.2011.41

577 [34] Edgar RC. UPARSE: highly accurate OTU sequences from microbial amplicon reads.

578 Nat. Methods. 2013; 10(10): 996. doi: 10.1038/nmeth.2604

579 [35] Logares R. Workflow for analysing MiSeq amplicons based on Uparse v1.5. Zenodo 2017; 580 10: 5281. doi: 10.5281/zenodo.259579

581 [36] Zhang J, Kobert K, Flouri T, Stamatakis A. PEAR: a fast and accurate Illumina Paired582 End read merger. Bioinformatics 2014; 30(5): 614-620. doi: 10.1093/bioinformatics/btt593

583 [37] Edgar RC. Search and clustering orders of magnitude faster than BLAST. Bioinformatics 584 2010; 26(19): 2460-2461. doi: 10.1093/bioinformatics/btq461

585 [38] Quast C, Pruesse E, Yilmaz P, Gerken J, Schweer T, Yarza P, et al. The SILVA ribosomal 586 RNA gene database project: improved data processing and web-based tools. Nucleic Acids 587 Res. 2013; 41(D1): D590-D596. doi: 10.1093/nar/gks1219

588 [39] Lahti L, Shetty S, Blake T, Salojarvi J. Microbiome R package; 2017. Tools Microbiome 589 Anal R.

590 [40] Oksanen J, Blanchet F, Kindt R, Legendre P, Minchin P, O’Hara R. Vegan: Community 591 Ecology Package; 2018. R package vegan, vers. 2.2-1.

592 [41] Wickham H. Ggplot2: Elegant Graphics for Data Analysis. Springer-Verlag, New York; 593 2009. http://ggplot2.org.

594 [42] Kolde R, Kolde MR. Package 'Pheatmap'; 2018. R version 2.10-1.

595 [43] Kováč L. Ice caves. In: In: Moldovan OT, Kováč L, Halse S, editors. Cave Ecology. Cham: 596 Springer; 2018. pp. 331-349. 
597 [44] Felestrino ÉB, Vieira IT, Caneschi WL, Cordeiro IF, Assis RDAB, Lemes CGC, et al.

598 Biotechnological potential of plant growth-promoting bacteria from the roots and rhizospheres

599 of endemic plants in ironstone vegetation in southeastern Brazil. World J. Microbiol.

600 Biotechnol. 2018; 34(10): 1-14. doi: 10.1007/s11274-018-2538-0

601 [45] Parker CW, Auler AS, Barton MD, Sasowsky ID, Senko JM, Barton HA. Fe (III) reducing 602 microorganisms from iron ore caves demonstrate fermentative Fe (III) reduction and promote 603 cave formation. Geomicrobiol. J. 2018; 35(4): 311-322. doi: 10.1080/01490451.2017.1368741

604 [46] Paula CCP, Montoya QV, Meirelles LA, Farinas CS, Rodrigues A, Seleghim MH. High 605 cellulolytic activities in filamentous fungi isolated from an extreme oligotrophic subterranean 606 environment (Catão cave) in Brazil. An. Acad. Bras. Ciênc. 2019; 91(3). doi: 10.1590/0001607 3765201920180583

608

[47] Souza PNDC, Tavares DG, Souza CRF, Martinez MLL, Oliveira WP, Guimarães LHS, 609 Cardoso PG. Spray Drying of Coloring Extracts Produced by Fungi Isolated from Brazilian 610 Caves. Braz. Arch. Biol. Technol. 2020; 63. doi: 10.1590/1678-4324-2020190024

611 [48] Marques EL, Silva GS, Dias JC, Gross E, Costa MS, Rezende RP. Cave drip water-related 612 samples as a natural environment for aromatic hydrocarbon-degrading bacteria. 613 Microorganisms 2019; 7(2): 33. doi: 10.3390/microorganisms7020033

614 [49] Mandal S, Chatterjee R, Kumar NS. Dominant bacterial phyla in caves and their predicted 615 functional roles in C and N cycle. BMC Microbiol. 2017; 17(1): 90. doi: 10.1186/s12866-017$616 \quad 1002-x$

617 [50] Tomczyk-Żak K, Zielenkiewicz U. Microbial diversity in caves. Geomicrobiol. J. 2016; 618 33(1): 20-38. doi: 10.1080/01490451.2014.1003341

619 [51] Oliveira C, Gunderman L, Coles CA, Lochmann J, Parks M, Ballard E, et al. 16S rRNA 620 gene-based metagenomic analysis of Ozark cave bacteria. Diversity 2017; 9(3): 31.

621 [52] Zhu HZ, Zhang ZF, Zhou N, Jiang CY, Wang BJ, Cai L, Liu SJ. Diversity, distribution 622 and co-occurrence patterns of bacterial communities in a karst cave system. Front. Microbiol. 623 2019; 10: 1726. doi: 10.3389/fmicb.2019.01726 
624 [53] Man B, Wang H, Yun Y, Xiang X, Wang R, Duan Y, Cheng X. Diversity of fungal communities in Heshang Cave of Central China revealed by mycobiome-sequencing. Front. Microbiol. 2018; 9: 1400. doi: 10.3389/fmicb.2018.01400

627

[54] Biswas D, Biswas J. Major Deteriorative, Pathogenic and Beneficial Fungi Reported from Various Subterranean Caves of the World: A Mini Review. Int. J. Ecosyst. 2017; 7(1): 11-16. doi: 10.5923/j.ije.20170701.02

[55] Pfaller MA, Diekema DJ. Rare and emerging opportunistic fungal pathogens: concern for resistance beyond Candida albicans and Aspergillus fumigatus. J. Clin. Microbiol. 2004; 42(10): 4419-4431. doi: 10.1128/JCM.42.10.4419-4431.2004

633 [56] Chlebicki A, Jakus N. Halotolerant and chaotolerant microfungi from littoral anchialine 634 caves Golubinka and Medova Buža (Croatia). J. Caves Karst Stud. 2019; 81(3). doi: 635 10.4311/2016MB0149

[57] Yan N, Marschner P, Cao W, Zuo C, Qin W. Influence of salinity and water content on 637 soil microorganisms. Int. Soil Water Conse. 2015; 3(4): 316-323. doi: 10.1016/j.iswcr.2015.11.003

639 [58] Werrett S. Fireworks and Color in the Sixteenth and Seventeenth Centuries. Early Sci. 640 Med. 2015; 20(4-6): 458-477. doi: 10.1163/15733823-02046p07

641 [59] Haferburg G, Gröning JA, Schmidt N, Kummer NA, Erquicia JC, Schlömann M. 642 Microbial diversity of the hypersaline and lithium-rich Salar de Uyuni, Bolivia. Microbiol. Res. 643 2017; 199: 19-28. doi: 10.1016/j.micres.2017.02.007

644 [60] Oren A. Halophilic archaea on Earth and in space: growth and survival under extreme 645 conditions. Phil. Trans. R. Soc. A. 2014; 372: 20140194. doi: 10.1098/rsta.2014.0194

646 [61] Yadav AN, Sharma D, Gulati S, Singh S, Dey R, Pal KK, et al. Haloarchaea endowed 647 with phosphorus solubilization attribute implicated in phosphorus cycle. Sci. Rep. 2015; 5(1): 648 1-10. doi: 10.1038/srep12293

649 [62] Bryant DA, Frigaard NU. Prokaryotic photosynthesis and phototrophy illuminated. Trends 650 Microbiol. (2006); 14(11): 488-496. doi: 10.1016/j.tim.2006.09.001 
[63] Panosyan H, Hakobyan A, Birkeland NK, Trchounian A. Bacilli community of saline alkaline soils from the Ararat plain (Armenia) assessed by molecular and culture-based methods. Syst. Appl. Microbiol. 2018; 41: 232-240. doi: 10.1016/j.syapm.2017.12.002

[64] Grube M, Muggia L, Gostinčar C. Niches and adaptations of polyextremotolerant black fungi. In: Seckbach J, Oren A, Stan-Lotter H, editors. Polyextremophiles. Dordrecht: Springer; 2013. pp. 551-566.

[65] Mota EA, Felestrino ÉB, Leão VA, Guerra-Sá R. Manganese (II) removal from aqueous solutions by Cladosporium halotolerans and Hypocrea jecorina. Biotechnol. Rep. 2020; 25: e00431. doi: 10.1016/j.btre.2020.e00431

[66] Hansen AJ, Risser PG, di Castri F. Epilogue: biodiversity and ecological flows across ecotones. In: Hansen AJ, di Castri F, editors. Landscape Boundaries. New York: Springer; 1992. pp. 423-438.

[67] Yao Z, Dong T, Zheng G, Fu J, Li S. High endemism at cave entrances: a case study of spiders of the genus Uthina. Sci. Rep. 2016; 6(1): 1-9. doi: 10.1038/srep35757

667 Fig S1. Detailed map of the Terra Ronca - Malhada subterranean system. Highlight for the (A) 668 Terra Ronca I (TR cave) and (B) Terra Ronca II caves. Map: Bambuí Speleological Research 669 Group - GBPE.

670 S2 Appendix. Prokaryotical OTU (Operational Taxonomic Unit) table.

671 S3 Appendix. Fungal OTU (Operational Taxonomic Unit) table.

672

\section{FIGURES}

675 Fig 1. Map of Lapa de Terra Ronca I cave (TR cave) located in a Brazil Central region, and 676 the photos shows the surface (A), external (B) and internal (C) view of entrance area and the 677 dark zone ( $\mathrm{D}$ and $\mathrm{E}$ ). The dots show the replicates samples in the map at entrance cave (green) 678 and dark zone (red). Surface samples were collected 50 meters far from cave entrance (map: 679 Grupo Bambuí de Pesquisas Espeleológicas - GBPE). 
680 Fig 2. Relative abundance of prokaryotic (A) and fungal (B) communities at the Class level in 681 TR cave during wet (April / 2016) and dry (October / 2016) season. Only the 10 most abundant 682 classes were shown, which less abundant classes being grouped into "Others".

683 Fig 3. Richness (Chao1), Diversity (Shannon) and Dominance (Simpson) indices of microbial 684 communities in three different habitats (surface, entrance and dark zone) at TR cave.

685 Fig 4. (A) Principal Coordinate Analysis (PCoA) plot based on weighted Unifrac results and 686 (B) Canonical Correspondence Analysis (CCA) of microbiome data and environmental factors 687 among the whole cave ecosystem, using Bray-Curtis distance and 999 permutations. Only 688 environmental factors with p-values $<0.05$ are marked at the graph. Samples from surface, 689 entrance and dark zones are highlighted in blue, green, and orange, respectively.

690 Fig 5. Heatmap of microbiome taxons with relative abundance $\geq 1 \%$ (core microbiome) from 691 different habitats in the TR cave. Samples from surface, entrance and dark zones are 692 highlighted in blue, green, and red, respectively. Fungal taxa are highlighted in dark blue, while 693 bacteria are grey, and archaea are purple. 
702 Table 1. Mean values and standard deviations of physical (substrate moisture, air temperature, air humidity and luminosity) and chemical ( $\mathrm{pH}$, salinity, organic 703 carbon $(\mathrm{OC})$ and nitrogen $(\mathrm{N})$ ) in TR cave on the surface, entrance and subterranean sample sites during wet (April 2016) and dry (October 2016) seasons.

\begin{tabular}{|c|c|c|c|c|}
\hline ENVIRONMENTAL PARAMETERS & Season & Surface & Entrance & Dark zone \\
\hline \multirow[t]{2}{*}{ Substrate moisture $(\%)$} & wet & $5.60 \pm 3.85^{\mathrm{a}}$ & $4.03 \pm 2.54^{\mathrm{a}}$ & $3.39 \pm 1.99^{\mathrm{a}}$ \\
\hline & dry & $1.13 \pm 0.56^{\mathrm{a}}$ & $5.86 \pm 1.91^{\mathrm{b}}$ & $5.91 \pm 1.32^{b}$ \\
\hline \multirow[t]{2}{*}{ Temperature $\left({ }^{\circ} \mathrm{C}\right)$} & wet & $26.85 \pm 0.53$ & $28.33 \pm 0.55$ & $26.63 \pm 0.98$ \\
\hline & dry & $29.25 \pm 0.10$ & $29.25 \pm 0.10$ & $27.38 \pm 0.21$ \\
\hline \multirow[t]{2}{*}{ Air humidity (\%) } & wet & $73.01 \pm 4.24$ & $66.23 \pm 0.97$ & $76.71 \pm 13.96$ \\
\hline & dry & $68.86 \pm 0.95$ & $64.81 \pm 3.93$ & $68.11 \pm 1.66$ \\
\hline \multirow[t]{2}{*}{ Luminosity (Lux) } & wet & $1835.33 \pm 71.8$ & $43.16 \pm 9.3$ & 0 \\
\hline & dry & $879.6 \pm 161.6$ & $233.8 \pm 57.3$ & 0 \\
\hline \multirow[t]{2}{*}{ pH } & wet & $8.88 \pm 0.14$ & $7.49 \pm 1.58$ & $7.69 \pm 0.25$ \\
\hline & dry & $8.69 \pm 0.29$ & $7.98 \pm 0.75$ & $7.59 \pm 0.10$ \\
\hline \multirow[t]{2}{*}{ Salinity (\%) } & wet & $0.067 \pm 0.007$ & $2.366 \pm 0.070$ & $0.020 \pm 0.001$ \\
\hline & dry & $0.227 \pm 0.007$ & $4.426 \pm 0.459$ & $0.111 \pm 0.014$ \\
\hline \multirow[t]{2}{*}{ OC $\left(\mathrm{mg} \mathrm{kg}^{-1}\right)$} & wet & $820.37 \pm 71.61$ & $1008.20 \pm 700.86$ & $448.93 \pm 145.67$ \\
\hline & dry & $824.48 \pm 700.84$ & $1170.71 \pm 1044.51$ & $334.98 \pm 51.23$ \\
\hline \multirow[t]{2}{*}{$\mathrm{N}\left(\mathrm{mg} \mathrm{kg}^{-1}\right)$} & wet & $0.055 \pm 0.040$ & $0.078 \pm 0.059$ & $0.036 \pm 0.004$ \\
\hline & dry & $0.075 \pm 0.047$ & $0.025 \pm 0.002$ & $0.025 \pm 0.007$ \\
\hline
\end{tabular}

Täfe 2. Mean values and standard deviations of chemical composition of the substrate (wt.\%) in TR cave on surface, entrance and dark sites during wet (Ap161/2016) and dry (October/2016) season.

\begin{tabular}{|c|c|c|c|c|c|c|c|c|c|c|c|c|}
\hline Sample Sites & Season & 0 & $\mathrm{Si}$ & $\mathrm{Al}$ & $\mathrm{Fe}$ & $\mathrm{Cu}$ & $\mathbf{K}$ & $\mathrm{Mg}$ & $\mathrm{Ca}$ & $\mathrm{Cl}$ & $\mathbf{S}$ & $\mathbf{P}$ \\
\hline \multirow[t]{2}{*}{ Surface } & wet & $58.9 \pm 3.1$ & $18.1 \pm 3.5$ & $3.2 \pm 1.6$ & $1.7 \pm 0.8$ & $0.8 \pm 0.4$ & $0.6 \pm 0.2$ & $0.3 \pm 0.2$ & $0.1 \pm 0.1$ & NA & NA & NA \\
\hline & dry & $51.9 \pm 2.2$ & $28.4 \pm 5.6$ & $1.6 \pm 0.2$ & $0.7 \pm 0.2$ & $0.7 \pm 0.3$ & $0.2 \pm 0.09$ & $0.2 \pm 0.05$ & $0.07 \pm 0.05$ & NA & NA & NA \\
\hline \multirow[t]{2}{*}{ Entrance } & wet & $58.1 \pm 5.2$ & $35.0 \pm 1.2$ & $5.4 \pm 2.7$ & $2.5 \pm 1.3$ & $1.3 \pm 0.1$ & $0.4 \pm 0.2$ & $17.3 \pm 5.4$ & $1.9 \pm 2.1$ & $0.04 \pm 0.1$ & $0.2 \pm 0.1$ & NA \\
\hline & dry & $60.5 \pm 0.7$ & $30.5 \pm 9.7$ & $4.4 \pm 2.2$ & $2.0 \pm 1.2$ & $1.3 \pm 0.8$ & $0.9 \pm 0.3$ & $12.5 \pm 5.6$ & $3.9 \pm 0.9$ & $0.04 \pm 0.1$ & $0.9 \pm 0.5$ & $1.5 \pm 0.3$ \\
\hline \multirow[t]{2}{*}{ Dark } & wet & $56.3 \pm 3.6$ & $22.1 \pm 6.2$ & $2.1 \pm 1.1$ & $1.1 \pm 0.6$ & $1.2 \pm 0.1$ & $0.2 \pm 0.2$ & $0.1 \pm 0.1$ & $0.2 \pm 0.1$ & NA & NA & NA \\
\hline & dry & $59.9 \pm 4.3$ & $28.5 \pm 7.6$ & $1.6 \pm 0.4$ & $0.9 \pm 0.5$ & $0.7 \pm 0.6$ & $0.07 \pm 0.1$ & NA & $0.1 \pm 0.1$ & NA & NA & NA \\
\hline
\end{tabular}


bioRxiv preprint doi: https://doi org/10.1101/2021.12.02 470950; this version posted December 2,2021 . The copyright holder for this

709 Raw sequence data from this study can be downloaded from National Center for Biotechnology

710 Information (NCBI) Sequence Read Archive (SRA) with accession number PRJNA723998

711 (16S) and PRJNA724003 (ITS).

712

\section{$71311 \quad$ Conflict of Interest}

714 The authors declare that they have no conflict of interest.

715

$71612 \quad$ Author Contributions

717 PAULA, CCP conceived and designed the study, responsible for chemical and molecular 718 analyzes and wrote the paper with input from all authors. SELEGHIM, MER was in charge of 719 the funding budgets and wrote the paper. BICHUETTE, ME contributed to data analyses, 720 coordinated the field sampling program and contributed to writing of the paper. SIROVÁ, D 721 and SARMENTO, H contributed to data analyses and writing of the paper. FERNANDES, CC and KISHI, LT were involved in the sequencing of the $16 \mathrm{~S}$ samples.

723

$724 \quad 13 \quad$ Funding

725 The study was supported by Coordenação de Aperfeiçoamento de Pessoal de Nível Superior 726 Brasil (CAPES) - Finance Code 001 awarded to CCPP and Fundação de Amparo à Pesquisa do Estado de São Paulo (FAPESP, 2015/24763-9) awarded to MHRS. 


\section{LAPA DE TERRA RONCA I}
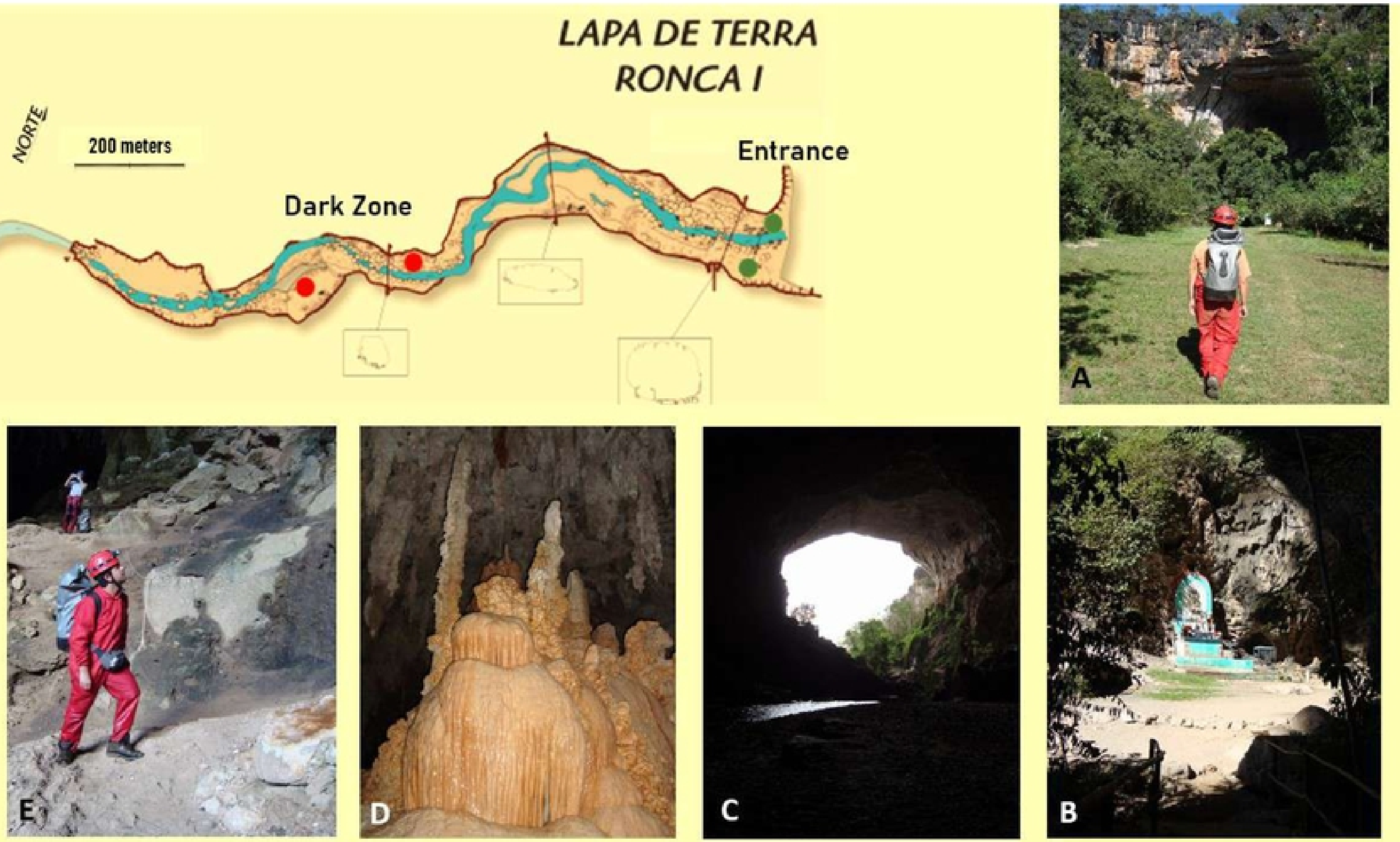

\section{Figure}




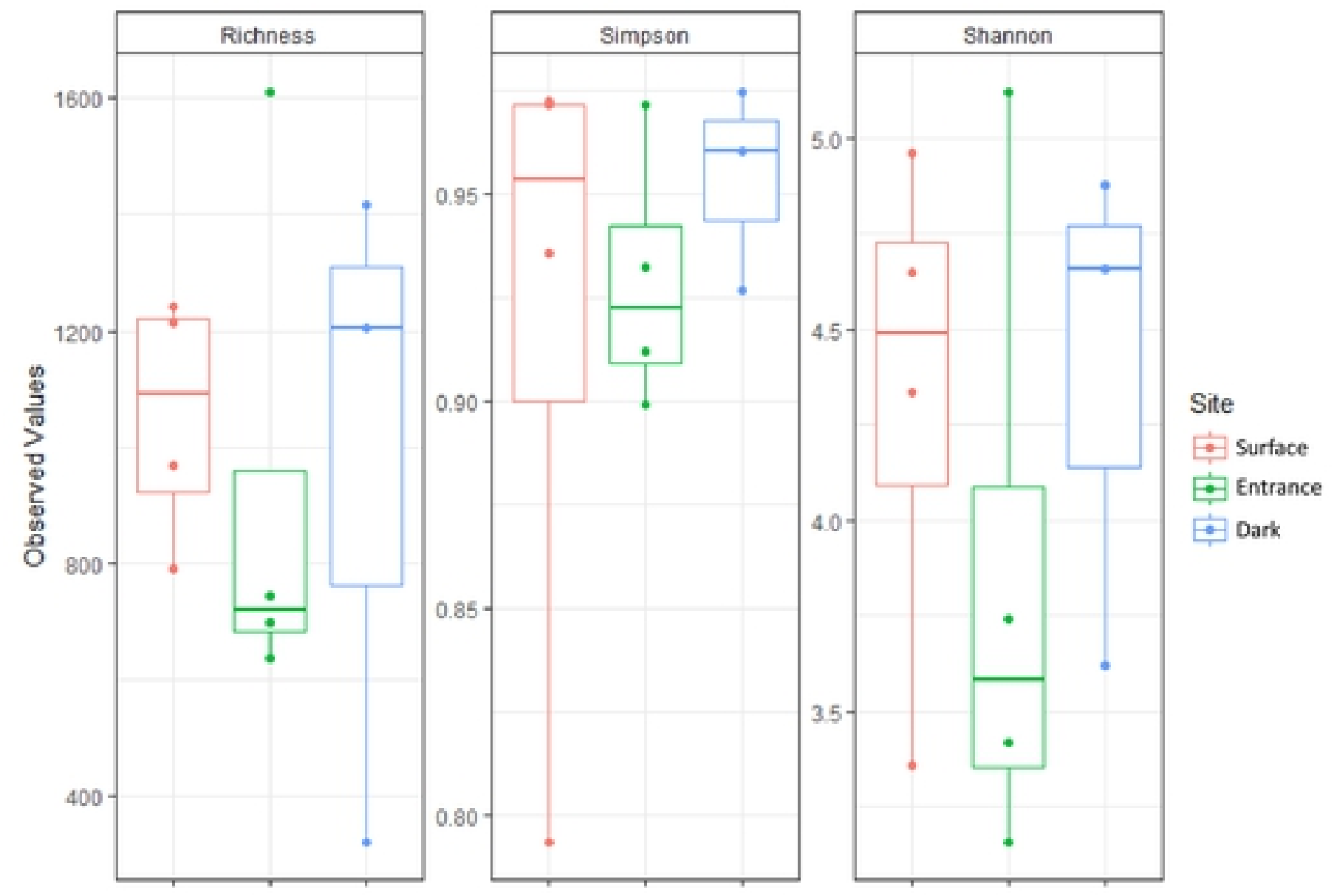

Figure 

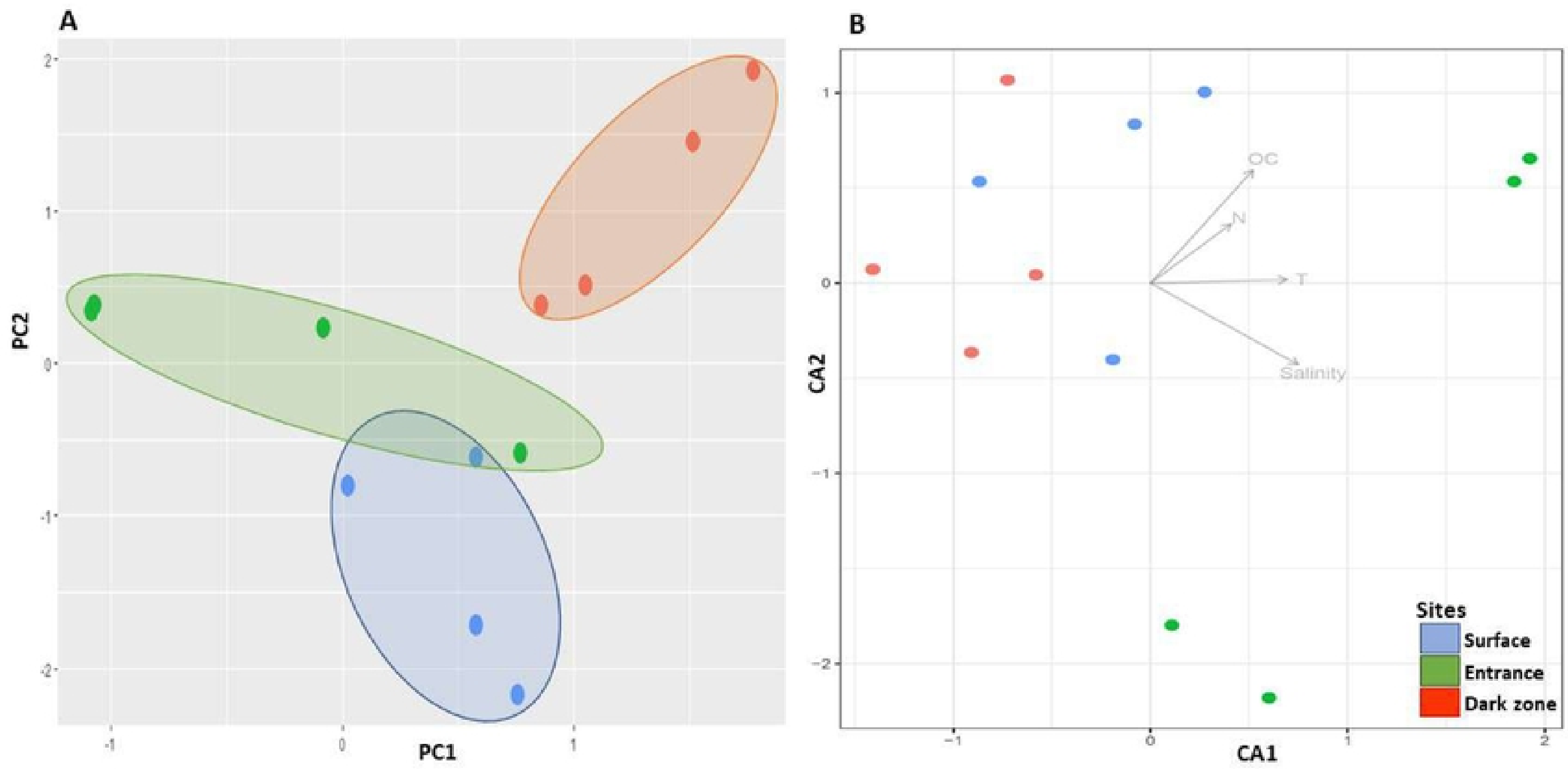

Figure 


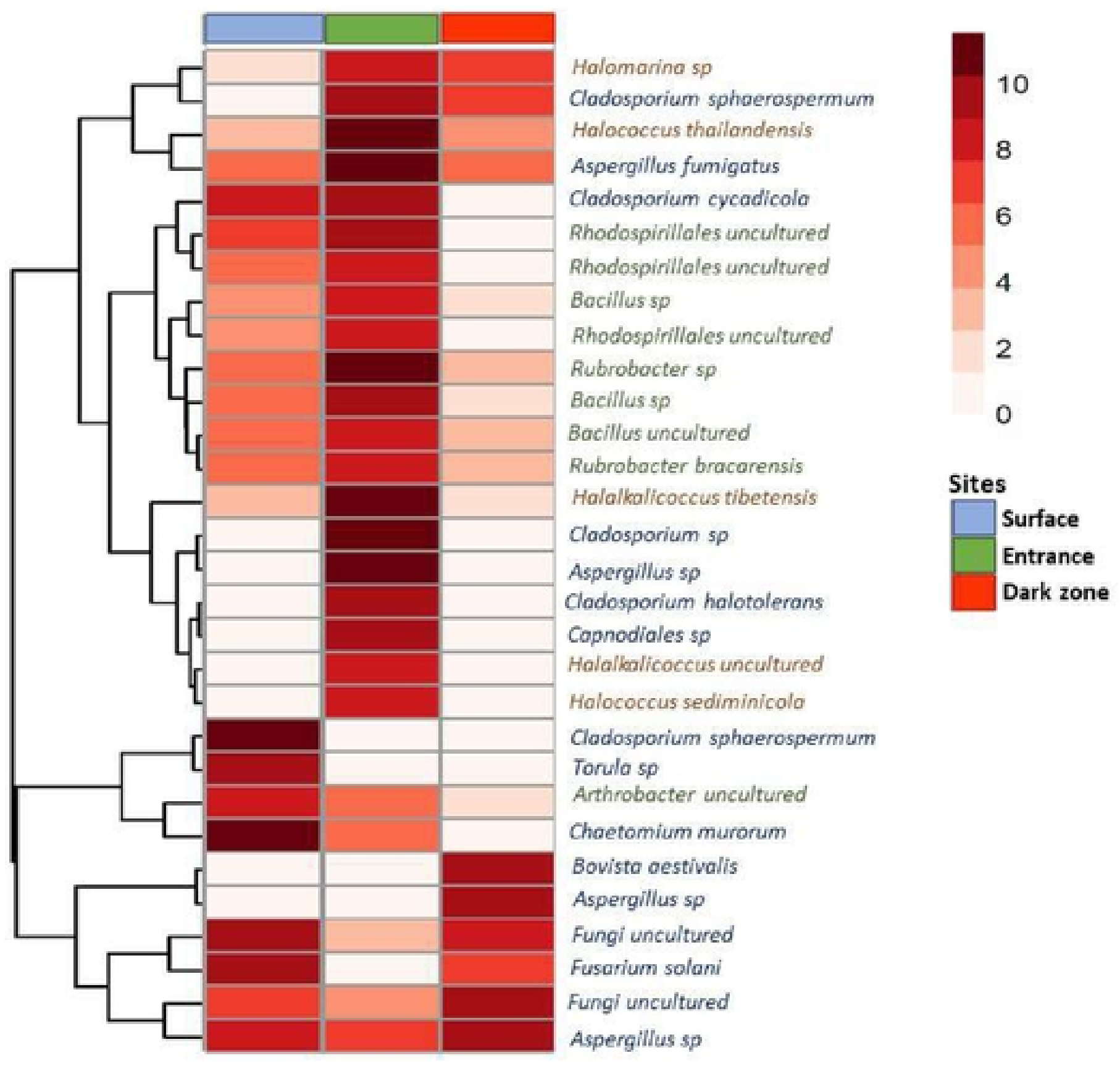

\section{Figure}

